\title{
ESTEREÓTIPO, PRECONCEITO E ASSÉDIO NAS TRAJETÓRIAS DE EXPATRIADAS BRASILEIRAS
}

\author{
STEREOTYPE, PREJUDICE AND HARASSMENT IN THE TRAJECTORIES OF BRAZILIAN FEMALE \\ EXPATRIATES
}

Recebido em 13.10.2020 Aprovado em 20.05.2021

Avaliado pelo sistema double blind revien

DOI: https://doi.org/10.12712/rpca.v15i1.46524

\author{
Aline Mendonça Fraga \\ alinemf.adm@gmail.com \\ Programa de Pós-Graduação em Administração/Universidade Federal do Rio Grande do Sul - Porto Alegre/RS, \\ Brasil \\ https://orcid.org/0000-0002-4240-464X
}

\section{Shalimar Gallon}

shalimargallon@gmail.com

Programa de Pós-Graduação em Administração/Faculdade Meridional (IMED) - Passo Fundo/RS, Brasil https://orcid.org/0000-0002-8830-4433

\section{Elem Rabelo Duarte Vaz}

elemduartevaz@gmail.com

Programa de Pós-Graduação em Administração/Faculdade Meridional (IMED) - Passo Fundo/RS, Brasil

http://orcid.org/0000-0002-9584-4497

\section{Resumo}

O presente estudo analisa as trajetórias de mulheres brasileiras expatriadas com relação a estereótipos, preconceitos e experiências de assédio vivenciadas. É uma pesquisa qualitativa, de caráter exploratório, com entrevistas de 20 participantes. Os dados foram analisados por meio da análise de conteúdo. A despeito de as mulheres altamente qualificadas e com status de mobilidade internacional constituírem uma elite no exterior, os privilégios não eliminam estereótipos, preconceitos e situações de assédio, quer por serem mulheres, quer por serem brasileiras ou por ambos os motivos, sobretudo em áreas de trabalho com pouca representatividade feminina.

Palavras-chave: Expatriação. Mulheres. Gênero. Assédio. Gestão de Pessoas

\begin{abstract}
This study aims to analyze the trajectories of Brazilian female expatriates related to their experiences of stereotypes, prejudices, and harassment. We took qualitative exploratory research with 20 expatriate women. The data were collected through individual interviews and were analyzed through content analysis. Despite being an elite abroad - highly qualified women with the status of international mobility, the privileges do not eliminate stereotypes, prejudices, and harassment situations, either because they are women, or because they are Brazilian, or both, especially in work areas with little female representation. Keywords: Expatriation. Women. Gender. Harassment. Human Resources Management.
\end{abstract}




\section{Introdução}

Historicamente, os homens compõem a maioria das pessoas expatriadas por organizações, ao passo que as mulheres formam, majoritariamente, o grupo de familiares acompanhantes (Brookfield Global Relocation Services [BGRS], 2016; Slobodin, 2019; Schnurr, Zayts, Schroeder, \& Le Coyte-Hopkins, 2019). À parte as dificuldades inerentes à expatriação, como o equilíbrio entre trabalho e família, a comunicação, o ajustamento cultural e o isolamento (Calderon, Guedes, Malheiros, \& Carvalho, 2016; Prestes, Grisci, \& Fraga, 2016; Langinier \& Froehlicher, 2016), as mulheres podem enfrentar outras barreiras pelo simples fato de serem mulheres em um mundo pensado e dominado por homens (Oliveira, Gaio, \& Bonacim, 2009; Eccel \& Grisci, 2011).

A escassez de mulheres expatriadas e a persistência da discriminação de gênero destacam-se como outros obstáculos enfrentados pelas expatriadas (Nunes \& Casaca, 2015; Bader, Stoermer, Bader, \& Schuster, 2018; Shortland \& Perkins, 2020). Ao chegarem ao país de destino, as brasileiras deparam-se com constantes atos discriminatórios plenos de estereótipos e preconceitos que podem culminar em assédio. Quando se pensa na cultura brasileira, inevitavelmente a ela são associadas características marcantes, como erotismo e sexualidade, expressas na maneira de vestir, na música e na dança (Freitas, 2001; Gomes, 2013).

Conforme evidenciado no estudo de Bader et al. (2018), na maior parte da revisão de literatura encontrada, apenas um país ou uma região geográfica foi pesquisada e as mulheres foram trabalhar em contextos distintos (Linehan \& Scullion, 2004; Janssens, Cappellen, \& Zanoni, 2004; PwC, 2015). Isso dificulta encontrar consenso sobre os limites e as potencialidades do tema. Considerando a pouca proporção de mulheres expatriadas ( $\mathrm{PwC}, 2015)$, as respostas encontradas nas pesquisas realizadas, sejam quantitativas ou qualitativas, mostram-se insuficientes para generalizações e ademais apresentam ambiguidades. Ao mesmo tempo em que os estudos tentam provar que as mulheres são bem-sucedidas quando expatriadas, demonstram serem elas usualmente preteridas nas missões ao exterior, destacando o sedentarismo involuntário vivenciado por mulheres que buscam a mobilidade em suas carreiras (Fraga \& Rocha-de-Oliveira, 2020).

A perceptível invisibilidade das mulheres brasileiras expatriadas é reforçada pela pouca discussão sobre o assunto no Brasil. Ela poderia ser resultante da incipiente discussão sobre igualdade de gênero, entretanto pesquisas internacionais demonstram que a situação é comum em outros países. A pouca representatividade de mulheres em expatriações parece ser reflexo da divisão sexual do trabalho e dos papéis de gênero atribuídos e socialmente construídos, que se afirmam no mercado de trabalho e, consequentemente, nas oportunidades desiguais para homens e mulheres.

Embora a questão da diversidade de gênero seja bastante discutida, esse debate tem sido pouco aprofundado no âmbito internacional (Shortland \& Perkins, 2020). Visando contribuir com o processo de mudança percorrido pelas mulheres no contexto do trabalho, a fim de evidenciar os desafios e as barreiras por elas enfrentadas na expatriação, objetivo da presente pesquisa é analisar as experiências de assédio, preconceitos e estereótipos vivenciadas nas trajetórias de mulheres brasileiras expatriadas.

Por meio dos relatos de mulheres que, à época da participação na pesquisa, estavam ou haviam estado em experiência da expatriação, este estudo se propõe a contribuir com subsídios tanto para as empresas que estão implementando ou irão implementar o processo de expatriação quanto para as mulheres que buscam uma trajetória profissional no exterior. Nas seções subsequentes, abordam-se os desafios das mulheres na expatriação; contextualizam-se o assédio, os preconceitos e os estereótipos que as atingem; elucidam-se os procedimentos metodológicos do estudo; apresentam-se a análise e a discussão das informações coletadas; conclui-se com as considerações finais. 


\section{Desenvolvimento teórico}

\section{Os desafios de mulheres em contexto de expatriação}

A maior participação da mulher no mercado profissional e a liberação de costumes arraigados na cultura brasileira provocaram uma série de mudanças nos ambientes de trabalho, antes exclusivamente sob domínio masculino (Freitas, 2001). Há pouco mais de um século, mulheres brasileiras casadas só podiam trabalhar fora do lar, possuir conta bancária ou viajar mediante autorização dos maridos. Há menos de cem anos, elas não podiam votar nem serem candidatas a cargos políticos. A mulher que trabalhava fora de casa e mesmo aquela percebida como bem-sucedida na carreira passava por julgamentos morais por se desviar de seu papel social considerado como principal e natural - o de esposa e mãe (Freitas, 2001). Somente com a Constituição de 1998 foram firmados direitos iguais para homens e mulheres.

Após os anos 1980, observa-se a crescente colocação da mulher no mercado de trabalho, incluindo a atuação em posições mais elevadas hierarquicamente. Em geral, é nesses cargos que se encontram as pessoas que recebem convites para trabalho no exterior ou a ele se candidatam. Conforme pesquisa da PwC (2015), a cada quatro expatriações somente uma é realizada por mulher, embora de cada dez mulheres sete gostariam de trabalhar fora de seu país (PwC, 2015). Esses números podem variar, dependendo do setor de atuação da empresa, (Shortland \& Perkins, 2020), pois, em espaços de trabalho generificados (Fraga \& Rocha-de-Oliveira, 2020), a discriminação de gênero institucionalizada pode ser desencorajadora para potenciais expatriadas (Bader et al., 2018). Contraditoriamente, as empresas limitam a participação de mulheres no processo de expatriação, porém consideram a experiência internacional um requisito importante na ascensão organizacional (Nunes \& Casaca, 2015; PwC, 2015).

A insuficiência de exemplos de profissionais com carreiras internacionais (28,2\%); a ausência de representatividade de seu gênero na sociedade do país de destino $(28,2 \%)$; a necessidade de trabalhar mais do que seus pares para alcançar uma expatriação $(23,1 \%)$ são motivos que aparecem em proporção maior do que duas vezes como justificativa para as mulheres recusarem a oportunidade de serem expatriadas, na comparação com os homens (PwC, 2015). Esses motivos também são focalizados no estudo de Nunes e Casaca (2015) e no estudo de Shortland e Perkins (2020), ao evidenciarem que as mulheres têm de mostrar muito mais resultados para conseguirem ascender na carreira internacional.

Embora algumas empresas tenham tomado iniciativas para ampliar o número de mulheres executivas, a maioria não avançou nesse intento (Dawson, Ho, \& Kauffman, 2015; Bibi, 2016; Shortland \& Perkins, 2020; Bader et al., 2018). Apesar da ampliação da presença de mulheres em cargos de gestão, poucas executivas conseguem chegar ao topo da carreira (Bibi, 2016; Dawson et al., 2015), posição mais propensa à expatriação. Isto talvez ocorra porque as executivas ainda são cobradas por papéis sociais de mãe, esposa e de responsável pelos afazeres domésticos, o que não ocorre com os executivos. Por conseguinte, a não maternidade (Fidelis \& Mosmann, 2013) - um fenômeno recente, ainda difícil de ser compreendido - apresenta-se como escolha ou imposição, pois "para a mulher se equiparar pelo menos em alguns pontos ao homem casado e com filhos, muitas vezes ela precisa não se casar e decidir não ter filhos" (Hryniewicz \& Vianna, 2018, p. 340). Essa questão refere-se, sobretudo, a mulheres heterossexuais e cisgênero.

No âmbito da expatriação, dados mostram que 34\% das mulheres são solteiras e sem filhos/as e 17\% dos homens são solteiros e sem filhos/as (Tharenou, 2008). Estes achados corroboram uma pesquisa que revelou que 70\% dos homens expatriados são casados e apenas a metade das mulheres o são (PwC, 2015). No estudo de Kemp e Rickett (2017) com trabalhadoras estrangeiras nos Emirados Árabes Unidos, as participantes ingressaram no mercado de trabalho fora de seu país de origem por motivo da expatriação ou de seus maridos ou de seus pais, e não por escolha pessoal. 
As pesquisas indicam que, em comparação com os homens, há mais restrições nas possibilidades de mobilidade para mulheres (Fraga \& Rocha-de-Oliveira, 2020), acentuadas em âmbito internacional, devido às condições sociais impostas, principalmente àquelas com crianças com idade escolar (Tharenou, 2008). O estudo de Tharenou (2008) mostra que a decisão de expatriar é tomada de maneira diversa por homens e mulheres, devido às diferentes responsabilidades familiares que socialmente lhes são atribuídas. Ainda que os homens casados e com crianças, ao considerarem a expatriação, envolvam a família na tomada de decisão, o impacto negativo é mais evidenciado sobre as mulheres. Há resistência dos homens em considerar a disposição de abandonar ou redirecionar a própria carreira em razão do trabalho de suas esposas.

Esse contexto confirma que práticas organizacionais aparentemente neutras acabam moldando a estrutura do trabalho, reforçando a desigualdade de gênero (Joshi, Son, \& Roh, 2015). Isso ocorre porque as organizações "foram criadas em sua grande maioria por homens e para homens" (Oliveira et al., 2009, p. 92), refletindo estruturas organizacionais baseadas em experiências masculinas (Oliveira et al., 2009; Eccel, \& Grisci, 2011). As masculinidades possibilitam que os indivíduos que a elas aderem desfrutem de privilégios (Sang \& Calvard, 2019; Eccel \& Grisci, 2011), como a progressão de carreira (Eccel \& Grisci, 2011), implicando barreiras para as outras pessoas que não as reproduzem.

Há barreiras com mais ou com menos visibilidade, como enuncia o fenômeno 'teto de vidro', que se refere à barreira invisível para mulheres que buscam ascensão profissional (Ezzedeen, Budworth, \& Baker, 2015; Fraga \& Rocha-de-Oliveira, 2020). Avançando na discussão, as dinâmicas tensões entre sociedades, organizações e pessoas indicam mobilidades no labirinto das carreiras contemporâneas (Fraga \& Rocha-de-Oliveira, 2020), favorecendo a expatriação masculina (Altman \& Shortland, 2008; Shortland \& Perkins, 2020). A aceitação de que as mulheres são preteridas na mobilidade internacional - o teto de vidro da expatriação - insere o tema como mais um a ser discutido no já estabelecido discurso sobre discriminação de gênero na gestão, sinalizando uma segunda camada para o 'teto de vidro' (Altman \& Shortland, 2008; Insch, Mcintyre, \& Napier, 2008; Shortland \& Perkins, 2020).

As condições internas do país de destino podem agravar os desafios que as expatriadas enfrentam (Nunes \& Casaca, 2015; Bader et al., 2018; Kemp \& Rickett, 2017). Alguns países como China, Brasil, Índia, Estados Unidos (BGRS, 2016; Fraga, Prestes \& Grisci, 2019) e Emirados Árabes Unidos (Kemp \& Rickett, 2017) são considerados como bastante desafiadores para a população expatriada, devido à distância psíquica entre país de origem e país de destino (Tanure, Barcellos, \& Fleury, 2009; Prestes et al., 2016). Em países patriarcais, como os Emirados Árabes Unidos, as mulheres estrangeiras podem ter mais facilidade de trabalhar, especialmente no setor privado, por serem consideradas externas à sociedade local (Kemp \& Rickett, 2017).

As empresas devem permanecer atentas às ameaças físicas e psicológicas que as mulheres podem vir a sofrer em alguns países, já que estereótipos culturalmente naturalizados são transportados para os ambientes institucionais (Bader et al., 2018). Inclusive há possibilidade de, em situações mais extremas, as mulheres estrangeiras serem impedidas de trabalhem nas organizações nacionais (Kemp \& Rickett, 2017). Esse contexto implica maior propensão a comportamentos de assédio contra as expatriadas por meio de calúnias ou de comentários sexistas (Bader et al., 2018).

\section{Preconceito, estereótipo e assédio e as implicações para expatriadas brasileiras}

Preconceito refere-se a critérios de comparação, com fins depreciativos, de uma pessoa ou grupo em relação a outros, a fim de sustentar a discriminação, bem como a exclusão social (Borges \& Peixoto, 2011). Por exemplo, o tratamento de um grupo como excluído ou socialmente minorizado ocorre devido a certa característica analisada por sua semelhança ou diferença em relação ao grupo considerado hegemônico. No ambiente organizacional, os estereótipos moldam vieses conscientes ou inconscientes, e levam a ações discriminatórias (Tonelli, 2018). 
Com referência ao gênero, o preconceito é marcado por pensamentos sexistas ou machistas, que colocam as mulheres em condição subalterna aos homens. Estereótipos de gênero ocorrem quando pessoas são rotuladas e influenciadas a se adaptarem a agir de determinada forma em detrimento de outra (Duarte \& Spinelli, 2019). No âmbito social, os estereótipos de gênero são explorados por instituições diversas, como a mídia. As influências exercidas têm implicação nas interações sociais das pessoas por meio de experiências que podem ocorrer em um continum de comportamentos mais sutis - como o olhar - e de comportamentos mais flagrantes e prejudiciais - como como o assédio nas ruas e o estupro (Cheeseborough, Overstreet, \& Ward, 2020).

Nas organizações, preconceito e estereótipo podem levar à violência na forma de assédio moral, pautado em certa perversidade com a qual indivíduos expressam a necessidade de rebaixarem outras pessoas para demonstrar o próprio poder (Hirigoyen, 2001). Há uma busca imperativa por aprovação, admiração e a consequente manipulação para alcançá-las (Freitas, 2001). Frequentemente, o assédio moral inicia-se com o abuso de poder, através de atitudes desrespeitosas e formas sutis de violência. Nas organizações, o assédio moral é iniciado, muitas vezes, de forma insignificante, porém, com o passar do tempo, vai se intensificando pelo fato de as vítimas não formalizarem uma denúncia. As vítimas são submetidas a insinuações e a situação se agrava quando elas são colocadas em estado de inferioridade, provocando humilhação e queda da autoestima (Freitas, 2001).

A persistência de estereótipos, especialmente em função do gênero, é vista como umas das principais barreiras para que as mulheres ocupem cargos gerenciais e participem de processos de expatriação. Isso se deve ao fato de, social e culturalmente, alguns atributos ainda serem associados à feminilidade e considerados incompatíveis com as exigências de cargos de liderança e de mobilidade (Nunes \& Casaca, 2015). Conforme as análises de Freitas sobre assédio (2001), no caso de mulheres expatriadas, pode ocorrer devido ao sentimento de inveja por sua qualificação, já que, no exterior, podem encontrar superiores hierárquicos sem as mesmas qualificações que elas.

Quando mulheres brasileiras estão no exterior, podem sofrer mais discriminação em função de estereótipos sobre sua cultura, já que "as ideias de beleza, sensualidade e disponibilidade sexual parecem estar imbricadas entre si no imaginário de mulher brasileira" (Gomes, 2013, p. 874). O preconceito contra as mulheres brasileiras foi percebido por esposas de expatriados em Portugal, ao tentarem encontrar emprego, fazer amizades, procurar instituições de ensino e, até mesmo, ao procurarem apartamento para alugar, pois as pessoas pensavam que elas queriam alugar o imóvel para realizar relações sexuais com fins lucrativos (Gallon, Scheffer, Gomes, \& Corte, 2019).

Gomes (2013) corrobora os registros de Cheeseborough et al. (2020) sobre o papel da mídia na objetificação sexual da mulher. Especificamente sobre o estereótipo da mulher brasileira como hipersexualizada, Gomes (2013) observa que ele foi retomado pela indústria turística, no final do século $\mathrm{XX}$, a fim de atrair turistas europeus. O foco da publicidade brasileira - de empresas e do governo incluía cenas provocantes, que exploravam o corpo da mulher e o carnaval (Gallon et al., 2019). No entanto, nos últimos anos, algumas agências do governo brasileiro têm adotado a postura de, em suas campanhas, destacar mais o patrimônio cultural e histórico brasileiro (Gomes, 2013). Algumas mídias internacionais exploram a imagem da brasileira com reportagens sobre casamentos, construindo uma disputa inexistente entre portuguesas e brasileiras pelos homens locais (Gomes, 2013), o que produz mais um estereótipo negativo em relação às mulheres brasileiras.

Embora a imagem estereotipada da mulher brasileira seja associada ao histórico de imigrantes trabalhadoras sexuais, Gomes (2013) observa a importância de se analisar esse fenômeno pela articulação entre colonialismo e gênero. Os entrevistados da pesquisa de Gomes (2013) diferenciam as italianas (bonitas, porém não disponíveis para sexo por serem europeias) das cabo-verdianas e das brasileiras (bonitas e disponíveis). Â luz da colonialidade, a diferenciação citada pelos entrevistados mostra que as mulheres das ex-colônias portuguesas são vistas como disponíveis unicamente pelo fato de não serem europeias. Essa relação entre não ser europeia e disponibilidade sexual perpassa algumas dimensões 
físicas (o 'bumbum', a beleza), comportamentais (vontade social, facilidade para o sexo, andar mais despida), culturais (gostar de festas, dançar, ser alegre) e certas associações com a natureza (clima tropical, calor, paraíso) que os entrevistados supõem não serem próprias das europeias. A distinção entre Europa e Brasil é realçada na pesquisa: a primeira aparece como destino de turismo histórico-cultural e o segundo, como destino de turismo de praia. Essa dicotomia reporta ao imaginário colonial que idealizava as colônias como paraísos naturais e selvagens versus a Europa como civilização e cultura (Gomes, 2013). A violência sexual e a estigmatização da sexualidade das mulheres negras e indígenas, escravizadas no período da colonização, demonstram a construção de um 'corpo colonial' visto como disponível, alvo da opressão dos colonizadores (Gomes, 2013). Este processo sustenta o imaginário de que as mulheres brasileiras vão para a Europa - majoritariamente - para trabalhar na prostituição. Apesar de a análise estar focada em Portugal, o estudo ressalta que a colonialidade pode ser ressignificada para diferentes contextos, estando presente também nos Estados Unidos e em outros países da Europa (Gomes, 2013). Cheeseborough et al. (2020) ressaltam que os estereótipos de promiscuidade naturalizada, construídos sobre as mulheres não brancas no percurso da história colonial, são utilizados como justificativa para a violência social e sexual contra elas.

Como forma de blindar a situação de desvantagem, seja pelo gênero, seja pelo status de estrangeira (Rodriguez \& Ridgway, 2019), as mulheres, quando estão no exterior, podem recorrer a subterfúgios vinculados à adaptação à ordem masculina e à neutralidade de aspectos femininos. Fraga et al. (2019) abordam o caso de uma expatriada brasileira que corporifica a masculinidade como estratégia para viver na expatriação, caracterizando a si como 'um profissional', no masculino, buscando afastar-se tanto da imagem feminina como de outras mulheres. A profissional brasileira, apesar da condição privilegiada de expatriada - sobretudo comparada a outras mulheres imigrantes, muitas vezes empregadas em funções de baixo status e remuneração (Rydzik \& Anitha, 2020) - pode enfrentar, no exterior, os reflexos de um estereótipo sociocultural que extrapola para o ambiente organizacional e implica justificativas para preconceito, assédio e outras formas de violência.

\section{Procedimentos metodológicos}

A presente pesquisa tem uma abordagem qualitativa exploratória, realizada por meio da técnica de entrevistas individuais (Gaskell, 2018). O roteiro de entrevista semiestruturado continha perguntas embasadas no referencial teórico sobre as mulheres expatriadas e as experiências de estereótipos, preconceitos e assédio.

Participaram da pesquisa 20 mulheres brasileiras, expatriadas por no mínimo seis meses, com idades entre 24 e 50 anos, de diversas áreas de formação, que atuam em variados ramos empresariais e que foram transferidas para um total 11 países (Figura 1). A indicação de potenciais participantes foi impulsionada por contatos pessoais das pesquisadoras em empresas multinacionais e, posteriormente, uma expatriada foi indicando outra da mesma empresa ou que conheceu durante a expatriação, caracterizando a técnica de bola de neve. Seus nomes foram substituídos na pesquisa por topônimos de cidades do país de destino, para garantir-lhes o anonimato. 
Figura 1 - Caracterização das participantes

\begin{tabular}{|c|c|c|c|c|c|}
\hline Expatriada & $\begin{array}{c}\text { Idade (em } \\
\text { anos) na } \\
\text { primeira } \\
\text { expatriação }\end{array}$ & Formação & $\begin{array}{l}\text { Países de } \\
\text { destino }\end{array}$ & $\begin{array}{l}\text { Tempo } \\
\text { no } \\
\text { exterior } \\
\text { (anos) }\end{array}$ & $\begin{array}{c}\text { Acompanhante(s) na } \\
\text { expatriação }\end{array}$ \\
\hline Nova Iorque & 33 & Análise de Sistemas & EUA & 12 & Marido \\
\hline Los Angeles & 29 & Administração & EUA & 5 & Marido \\
\hline Kuwait & 24 & Engenharia Química & $\begin{array}{l}\text { Kuwait e } \\
\text { EUA }\end{array}$ & 5 & Não \\
\hline Berlim & 30 & Ensino Médio & $\begin{array}{l}\text { Alemanha e } \\
\text { EUA }\end{array}$ & 4,5 & Não \\
\hline Mumbai & 50 & $\begin{array}{c}\text { Comércio Exterior e } \\
\text { Direito }\end{array}$ & Índia & 4 & Não \\
\hline Munique & 24 & Engenharia de Materiais & Alemanha & 4 & Marido \\
\hline Pequim & 30 & Engenharia de Produção & China & 3,5 & Não \\
\hline Chicago & 29 & Publicidade e Propaganda & EUA & 3 & Marido \\
\hline Tijuana & 28 & Ensino Médio & México & 3 & Marido \\
\hline Houston & 37 & Ciência da Computação & EUA & 2,2 & Marido \\
\hline Filadélfia & 27 & Psicologia & EUA & 2 & Não \\
\hline Tóquio & 30 & Matemática & $\begin{array}{l}\text { Japão e } \\
\text { Chile }\end{array}$ & 2 & Não \\
\hline Phoenix & 29 & Turismo & EUA & 1,7 & Não \\
\hline Dallas & 29 & Administração & EUA & 1,5 & Marido \\
\hline Charlotte & 30 & Engenheira de Produção & EUA & 1,1 & Marido \\
\hline Montreal & 25 & Psicologia & Canadá & 1,2 & Não \\
\hline Singapura & 27 & Engenharia Metalúrgica & Singapura & 11 meses & Não \\
\hline Xangai & 45 & Administração & $\begin{array}{l}\text { China e } \\
\text { EUA }\end{array}$ & 9 meses & Marido e filhos \\
\hline Londres & 29 & Administração & Inglaterra & 7 meses & Não \\
\hline Valparaíso & 24 & Engenharia de Materiais & Chile & 6 meses & Não \\
\hline
\end{tabular}

Fonte: Elaborada pelas autoras (2020).

As entrevistas foram realizadas por Skype (Stewart \& Shamdasani, 2016) ou pessoalmente, conforme a localização e a preferência da participante. Mediante autorização, os diálogos foram gravados e transcritos. O processo de análise de conteúdo emergiu da dupla categorização: 'a vida além-fronteiras: contexto sociocultural da brasileira no exterior'; 'entre privilégios e prejuízos: o contex to do trabalho para uma expatriada brasileira', estando de acordo com as discussões propostas por Rodriguez e Ridgway (2019).

\section{Apresentação e análise dos resultados}

A análise dos resultados é apresentada em duas seções: a primeira descreve a vida além-fronteiras, mostrando o contexto sociocultural em que se inserem as brasileiras no exterior; a segunda expõe privilégios e prejuízos identificados no contexto laboral das expatriadas brasileiras.

\section{A vida além-fronteiras: contexto sociocultural de profissionais brasileiras no exterior}

Coerente com a literatura exposta, as participantes da pesquisa corroboram achados que indicam a menor disponibilidade de mobilidade das mulheres casadas - apesar da vontade individual (Tharenou, 2008; Fraga \& Rocha-de-Oliveira, 2020) - e a tendência de expatriação de profissionais jovens e sem acompanhantes (Polson, 2016). A maioria das entrevistadas são solteiras, 16 foram expatriadas quando tinham, no máximo, 30 anos. Nove delas são casadas. Somente uma entrevistada levou os filhos pequenos para o exterior, ratificando os resultados da pesquisa da PwC (2015). Esse ponto evidencia as barreiras à agência das mulheres em relação aos homens quanto a escolhas profissionais e familiares (Fidelis \& Mosmann, 2013), na tentativa de alcançarem, pelo menos em alguns pontos, oportunidades semelhantes às do homem casado e com filhos/as (Hryniewicz \& Vianna, 2018). 
De todos os casos analisados, quatro expatriadas tiverem a oportunidade de conciliar sua expatriação com a do cônjuge, indicando a tendência de casais dual career, que buscam equilibrar ambas as carreiras. Três casais trabalham na mesma empresa - o que facilitou o processo - e um, em empresas diferentes. Usualmente, o processo de expatriação é individual, sendo comum o cônjuge estar impedido de trabalhar no exterior, por ter visto de acompanhante. Em seu depoimento Houston explica: "dificilmente as pessoas vêm para cá trabalhando. Eles vêm mais como acompanhantes e depois de um ano, dois anos, eles conseguem alguma colocação. E essa era uma oportunidade de ouro para nós, porque a gente viria trabalhando e com o dobro do salário". Na conciliação da expatriação de ambos os cônjuges, as mulheres ampliam sua mobilidade (Fraga \& Rocha-de-Oliveira, 2020), sem que seus maridos estejam na posição de acompanhante, sem trabalho remunerado (Schnurr et al., 2019). Esse é um arranjo ainda restrito tanto no contexto familiar como no organizacional.

Os diferentes países de destino exigem mudanças no estilo de vida e na rotina das mulheres expatriadas. No contexto norte-americano, por exemplo, elas assumem mais as responsabilidades no cuidado da casa por causa dos custos e da cultura local - porque lá “o pessoal faz muito mais as coisas por si” (Houston) -, ao invés de contratarem empregadas domésticas e diaristas, como ocorre no Brasil. Quando em países muçulmanos, elas precisam se adaptar às influências da religião, como utilizar o "estacionamento para mulheres no shopping separado, numa área totalmente isolada" (Xangai). A segregação social das mulheres em alguns locais, ao mesmo tempo que fornece algum tipo de segurança, evitando assédio sexual e violências diversas (McLaughlin, Uggen, \& Blackstone, 2017), gera sentimentos de solidão e exclusão, o que se torna um agravante na expatriação (Altman \& Shortland, 2008).

O isolamento social também ocorre devido a condutas sociais diferentes, que enseja corroborar o estereótipo da mulher brasileira hipersexualizada. Singapura conta que, após ter sido notificada sobre o seu comportamento considerado inadequado para os costumes locais, acabou sendo socialmente isolada: "era uma academia só de mulher, cheguei no vestiário para me trocar, eu estava de top, não estava nem pelada, e vieram falar comigo que eu não podia trocar de roupa, só nas cabines. Eu ia todos os dias na academia, no mesmo horário, ninguém falava comigo, ninguém" (Singapura). Embora esse caso tenha ocorrido fora da empresa, o isolamento de uma pessoa no ambiente organizacional é entendido como uma forma de assédio moral, visto que o isolamento impulsiona a deterioração das relações, bem como a degradação da integridade da pessoa no ambiente de trabalho (Hirigoyen, 2001), especialmente quando associado à cultura do país de origem.

Considerada uma característica comum à mulher brasileira, a sensualidade (Gomes, 2013) aparece, nos relatos, em diferentes esferas sociais e em momentos de lazer, tanto na relação com homens como com outras mulheres do país de destino. Implica o desenvolvimento de estratégias por meio da mudança de hábitos e comportamentos, coerente com as três formas de resistência e reexistência - passiva, afirmativa, combativa - da mulher brasileira no exterior referidas por Gomes (2013). Londres busca desconstruir o discurso hegemônico por meio da estratégia de "trazer o meu namorado para conhecer todos os meninos que trabalham comigo, para que assim todos compreendam que apesar de eu ser mulher e brasileira, o que não ajuda muito fora, eu sou comprometida". Valparaíso afasta-se daquilo que é considerado brasilidade - após experiências de desconforto com olhares curiosos na academia, decidiu adotar outro estilo de roupa, que não marcasse o corpo, embora sua experiência tenha sido em um país latino, diferentemente de Singapura: "eu vou com uma calça de abrigo tamanho 46 e eu uso 36, e uma camiseta GG, e eu uso PP, e mesmo assim, eu entro na academia e as pessoas param o que estão fazendo para me olhar malhar. Eu não me sinto confortável de usar roupa de ginástica, não dá" (Valparaíso).

Montreal corrobora essa percepção e mostra a relação da sensualidade com as roupas de praia e as festas culturais do Brasil, como o carnaval: "quando eu ia para o chão de fábrica, eles me olhavam com um brilho no olho, parecia que eu estava descendo de biquíni, entrando na Sapucaî". Os relatos evidenciam que ser brasileira prevalece como um fator negativo, com base sobretudo no estereótipo ligado à sexualidade e à sensualidade acentuada (Gomes, 2013; Gallon et al., 2019), diretamente relacionado com 
a prostituição, mesmo que ela esteja em uma posição de privilégio, "é mulher, é brasileira, é estrangeira", destaca Londres. $\mathrm{Na}$ visão das entrevistadas, esses marcadores carregados de estereótipos alimentam preconceitos e são utilizados como justificativas para assédio, ocasionando inúmeros prejuízos para expatriadas brasileiras, quer no contexto sociocultural quer na vida além-fronteiras.

Os relatos das entrevistadas são coerentes com a explanação de Gomes (2013) e de Cheeseborough et al. (2020) sobre o papel da mídia na objetificação sexual da mulher, na qual os estereótipos da mulher brasileira e a hipersexualização foram enfatizados pela indústria turística para atrair europeus ao Brasil. A 'venda' desses estereótipos acaba sendo levada para o convívio social externo e interno às organizações, impulsionando episódios de discriminação e assédio contra as mulheres brasileiras que lá trabalham.

Ao ressignificar suas trajetórias, com resiliência e resistência (Rydzik \& Anitha, 2020), as participantes mostram as estratégias que a brasileira expatriada (Fraga et al., 2019) encontra para desenvolver formas de socialização dentro e fora do trabalho. Expõem como diferentes empresas que, em geral, destacam a globalização em seus negócios e o crescimento de valor com a contratação de profissionais de diferentes origens étnicas e geográficas, não têm atuado em políticas e práticas de Gestão de Pessoas que valorizem e principalmente respeitem essa diversidade.

Tanto a omissão das empresas em atuar contra vieses inconscientes (Tonelli, 2018) - ou seja, contra os estereótipos sociais relativos a gênero, etnia ou nacionalidade pertinentes ao caso das entrevistadas como a postura de neutralidade de gênero são prejudiciais ao avanço profissional das mulheres. Reconhecer as barreiras enfrentadas por elas em suas unidades deve ser uma premissa para articulação de políticas de igualdade, como problematizado por Shortland \& Perkins (2020). A ausência de suporte para a progressão de carreira pautada na equidade e em políticas de apoio à diversidade (Shortland \& Perkins, 2020) pode impedir que mulheres estrangeiras trabalhem em organizações nacionais (Kemp \& Rickett, 2017). Reconhecer e trabalhar as dificuldades com todas as pessoas contratadas é uma forma de valorizar a globalidade na empresa, bem como de promover condições de equidade e inclusão, independentemente de qualquer marcador social de diferença (Fraga \& Rocha-de-Oliveira, 2020).

\section{Entre privilégios e prejuízos: o contexto do trabalho para expatriadas brasileiras}

As entrevistadas relatam que, em alguns países, os preconceitos e os estereótipos em relação à mulher são mais acentuados, devido às estruturas históricas do país (Nunes \& Casaca, 2015) e/ou por terem ambientes institucionalizados como masculinos (Bader et al., 2018; Eccel \& Grisci, 2011). Por conseguinte, dependendo do país, "eu não posso trabalhar, no Irã, no Iraque, existe uma limitação" (Valparaíso), corroborando o exposto na literatura (Kemp \& Rickett, 2017). A resistência de gestores em escolherem mulheres para projetos internacionais pode estar relacionada à segurança (Nunes \& Casaca, 2015), mesmo em países ocidentais, como o Brasil, ou orientais, como a Índia (BGRS, 2016). Berlim relata uma experiência particular, vivida por ser mulher, pois tem a convicção de que um homem não passaria pela mesma situação:

Eu trabalhava de madrugada e tinha um garoto da linha de produção que me escrevia por e-mail porque ele não tinha coragem de falar pessoalmente comigo. Eu disse que ele não tivesse medo, que falasse comigo que não teria problema nenhum. Eu fui querer ser simpática e ele me esperou na saída. Eu tive que quase chamar a segurança para ele não me agarrar na porta da empresa. Eu imagino que com um homem, isso não aconteceria. E isso pode ser pelo fato de eu ser mulher, estrangeira, tem tudo isso (Berlim).

Para Kuwait, "a grande maioria das pessoas lá [no exterior] vão te enxergar como sexo fácil”, retratando a julgada disponibilidade sexual com a qual mulheres brasileiras são vistas, baseada sobretudo nas construções das dimensões físicas, comportamentais e culturais (Gomes, 2013). O preconceito contra a mulher perpassa frases comuns, como "isso não é coisa de mulher", encontrada no relato Valparaíso: 
“quando eu fui para a Bolívia, eu ouvi assim do coordenador: 'faz um favor, vai lá dentro, fala com o gerente e pede demissão. Isso aqui não é lugar para mulher. Tu não tem que estar aqui, vai pra casa, tu é uma mulher bonita, deve ter um marido lá te esperando, tu vai ficar suja, não faz isso"'. Sobressai, nessa situação, o questionamento sobre onde fica o lugar de mulher e o incômodo com uma mulher em posição distinta da esperada - como revelam Schnurr et al. (2019), não é esperado que seja a mulher quem se desloca para trabalhar, deixando seu marido em casa. Esse relato aproxima-se do que expressam Casaca e Nunes (2015), os quais destacam a força dos estereótipos socioculturais ligados à feminilidade, inadequados ao perfil de expatriada. É perceptível como posturas de insinuação, formas sutis de violência e falta de respeito, comuns ao início do assédio moral (Freitas, 2001), surgem disfarçadas de simples opinião sexista. Berlim concorda com a prevalência desse tipo de posicionamento para constituir assédio moral ou sexual, principalmente por trabalhar em um setor e em uma área considerados masculinos (Eccel \& Grisci, 2011; Bader et al., 2018), como retrata em sua fala:

Enorme, enorme [preconceito] o que eu tinha que ouvir de piadinhas, tem que ter muito jogo de cintura para não dar na cara de muita gente. E eu acho que por eu trabalhar na indústria automotiva e com informática, que são duas áreas onde a maioria das pessoas que trabalham são homens, então tem um preconceito muito grande, mesmo no Brasil, não foi só no exterior, eu tinha que ouvir muita piadinha (Berlim).

Apesar das conquistas e das mudanças, no mercado de trabalho, relativas à inserção das mulheres e à progressão em suas carreiras (Fraga \& Rocha de Oliveira, 2020), as práticas organizacionais são baseadas em experiências masculinas ou que supervalorizam masculinidades (Oliveira et al., 2009; Eccel, \& Grisci, 2011). Elas ocorrem sobretudo em contextos sócio-históricos, que costumam privilegiar homens ao referenciar um tipo profissional padrão. Esse contexto perpetua a desproporção entre mulheres e homens no ambiente de trabalho, por exemplo, na Índia, conforme evidencia Mumbai:

[...] não sei se me aceitaram ou se acabaram se acostumando à minha presença. Mas quando eu cheguei, havia apenas quinze mulheres trabalhando, era uma proporção de uma mulher por área e sempre em atividades de suporte. Essas mulheres também me viam de maneira estranha, principalmente no começo. Elas me olhavam como se eu fosse um E.T.” (Mumbai).

No âmbito do trabalho, práticas organizacionais aparentemente neutras ou que passam despercebidas, como a disposição de banheiros (Fraga et al., 2019), moldam estruturas generificadas (Fraga \& Rochade-Oliveira, 2020), que provocam distanciamentos e disputas, por vezes entre mulheres, e reforçam a desigualdade de gênero (Joshi et al., 2015), como evidenciado nesse relato:

Quando eu fui pro Chile, era eu e mais uma mulher da gerência na base inteira. A gente teve que brigar por quase um mês para ter um banheiro, e o papelzinho era um papel impresso no banheiro. Só tinham dois banheiros, aí um era para as outras 60 pessoas. Eu acho injusto 50 pessoas dividirem um banheiro e duas dividirem outro, mas por que não contratam 25 mulheres? Aí vai ter 25 em cada banheiro. Eu também não acho justo eu ter que usar um banheiro que 50 homens usam (Valparaíso).

Para as expatriadas, algumas condições de trabalho diferenciadas - por serem mulheres em espaços formados por uma maioria de homens e com arranjos masculinos -, apesar de facilitarem a atuação, fomentam noções de privilégios e, por consequência, preconceitos. Por vezes, as próprias expatriadas colocam-se contrárias a outras mulheres, buscando, em certa medida, neutralizar o gênero ou passarem despercebidas pelos homens (Fraga et al., 2019). Mumbai critica o fato de colegas mulheres, ao invés de reivindicarem políticas organizacionais que aumentem a participação e a igualdade de oportunidades para mulheres na organização, optaram por pedir benefícios simples, o que para ela corrobora a imagem de 
sexo frágil. Pode-se entender que, em alguns países e organizações, as políticas visando à equidade de gênero são tão distantes da realidade que as mulheres acabam se contentando com pequenas conquistas, as quais possivelmente mais reforçam a diferença do que denunciam a desigualdade: "Eu disse para elas: 'o que eu espero é que quando eu sair daqui o número de mulheres nessa empresa tenha crescido e que vocês, mulheres, comecem a ter uma visão diferente do mundo e de seu valor"”.

Além da discriminação, as mulheres também são assediadas por serem estrangeiras, pois "para eles é mais fácil conseguir alguma coisa com mulher estrangeira do que com mulher de lá, tem toda a questão de família" (Kuwait). Londres relata sua percepção: "o quão difícil é esse negócio de fazer networking no exterior, de achar mentores entre os seus diretores e sócios da empresa porque a relação é muito tênue. Entre você ser mentor e mentorado e acharem que a menina está dando em cima do cara porque ele é chefe [...]". Casos de assédio foram mencionados tanto em países em que as mulheres não têm liberdade para trabalharem, a exemplo do Kuwait, quanto em um país com considerável igualdade de gênero, como os Estados Unidos. A fala de Berlim corrobora a naturalização do assédio e a visão estereotipada da mulher brasileira:

O preconceito existe contra estrangeiro, existe contra a mulher brasileira. A primeira pergunta é se você sabe sambar, ou se você faz brazilian wax [depilação brasileira]. No momento em que você fala que é brasileira eles já te olham diferente, com um sorriso malicioso, seja homem ou mulher. Teve muita mulher que arrumou confusão, não comigo, mas com os maridos porque elas não queriam que eles falassem comigo. Essa visão da mulher brasileira fora do país, samba, carnaval, é real, todo mês eu acho que escuto esse tipo de piada. Nos Estados Unidos é até mais forte do que na Alemanha, pois aqui eles têm muito mais respeito e eles sabem muito mais coisas sobre o Brasil do que os americanos.

$\mathrm{Na}$ medida em que as experiências são particulares e envolvem influências de contextos sociais e culturais, do país e das próprias organizações, Nova Iorque considera que o ambiente de trabalho nos Estados Unidos é muito mais igualitário em relação à mulher quando comparado ao Brasil, especialmente no âmbito gerencial:

[...] nenhum colega meu no meu nível me pediu pra levantar e pegar um café no escritório, na mesma empresa, não é crítica à empresa, é a cultura no Brasil. E eu tô te dando um exemplo bem bobinho, mas a gente tá acostumada a ouvir e viver e aguentar no Brasil, no ambiente profissional, que aqui se sente que tem um ambiente com mais igualdade.

Kuwait relata sua percepção concordando com o exposto sobre a cultura brasileira: "as pessoas davam em cima sim, mas nada comparável a tu passar por uma obra, no Brasil, nada agressivo". Percebe-se que diante das constantes experiências de assédio, há uma espécie de limite considerado aceitável: "eu não sofri nenhum tipo de preconceito, de ser maltratada, mas eu sei de algumas meninas sim, que foi oferecido dinheiro em troca de sexo, para uma funcionária da mesma empresa, que trabalhava comigo" (Kuwait). Os relatos demonstram que prevalece a percepção de que o assédio é um problema inevitável na vivência das mulheres, já que as organizações refletem a sociedade onde estão inseridas, sendo preciso considerar os danos de enfrentar uma cultura misógina no trabalho (McLuaghlin et al., 2017), especialmente para brasileiras.

Conquanto seja um dos países considerados mais difíceis para adaptação (BGRS, 2016), ambas as expatriadas para a China, Pequim e Xangai, demonstraram impressões positivas do país, sobretudo na questão de gênero "aqui na China não tem problema algum, eles respeitam muito a hierarquia, eu não tenho problema" (Pequim). Xangai relata ser respeitada no ambiente de trabalho, mas observa um 
contexto semelhante ao brasileiro: mais homens que mulheres em cargos executivos, mesmo que elas tenham mais qualificação do que eles (Fraga \& Rocha-de-Oliveira, 2020), como mostra seu relato:

Eles respeitam muito a mulher no ambiente de trabalho. Tem mais homens, sim, mas tem muitas mulheres em cargos executivos. As mulheres são inteligentíssimas. Em geral, elas têm mais formação que os homens, mais instrução, e são muito respeitadas. Então, no ambiente de trabalho, eu não senti nenhuma distinção (Xangai).

Em que pese o status glamourizado da mobilidade, sobretudo a internacional (Fraga \& Rocha-de-Oliveira, 2020), as vivências de privilégios e prejuízos para mulheres são inseparáveis, de tal forma que uma série de condutas sociais e de normas organizacionais são arranjadas de modo a manter a ordem social de gênero (Rodriguez \& Ridgway, 2019). Quando se trata da experiência de mulheres, é indispensável considerar a hegemonia masculina. Mesmo em situação de elite privilegiada, como no caso das mulheres altamente qualificadas e expatriadas, as opressões de gênero não desaparecem, sendo intensificadas ou atenuadas conforme o contexto social, cultural e laboral.

\section{Considerações finais}

O presente estudo analisou as experiências de assédio, preconceitos e estereótipos vivenciadas por mulheres brasileiras envolvidas em processos de expatriação para diversos países. Mesmo com indícios de que não há falta de interesse das mulheres em trabalhar no exterior (Altman \& Shortland, 2008), a persistente sub-representação na mobilidade internacional (BGRS, 2016; Slobodin, 2019) tensiona os limites da vontade individual (Fraga \& Rocha-de-Oliveira, 2020), tendo em vista as barreiras impostas por diferentes estruturais sociais, com particularidades distintas a depender do contexto de origem e de destino.

Os resultados indicam que, na medida em que são ultrapassadas as barreiras impostas, sobretudo pelos marcadores de gênero e de nacionalidade, as expatriadas ampliam as possibilidades de carreira, após a expatriação, com reflexões críticas sobre o contexto sociocultural e laboral no exterior. As participantes aprofundaram o olhar sobre a desigualdade de gênero no Brasil, a partir de sua vivência internacional. Os países de destino da expatriação podem apresentar limitadores insuperáveis, já que há casos de proibição da transferência de estrangeiras para filiais no exterior, pois dependendo do país, surgem preocupações com a garantia física da expatriada.

Os resultados mostram que: (i) há preconceitos que originam vieses conscientes e inconscientes em relação à mulher brasileira expatriada, por causa da associação a dimensões físicas, comportamentais e culturais (Gomes, 2013) que amparam um imaginário construído sobre beleza, sensualidade e disponibilidade sexual; (ii) o imaginário desloca-se conforme o contexto social, cultural e laboral, sendo evidenciado também nas práticas das organizações; (iii) as expatriadas ressignificam suas trajetórias com resiliência e resistência, majoritariamente de modo individual, a fim de lidarem com os impactos de estereótipos, preconceitos e assédio nas relações organizacionais e sociais; (iv) é comum as expatriadas sofrerem atitudes discriminatórias, assédios morais e sexuais na experiência além-fronteiras, independentemente do país de destino, com pouca ou nenhuma responsabilização das empresas.

Conforme os resultados, as empresas brasileiras que atuam no exterior e as multinacionais com filiais no Brasil precisam estar atentas para o desenvolvimento de políticas e práticas voltadas à diversidade tanto de gênero como étnico-racial. Alinhadas às estratégias organizacionais, essas ações podem atenuar vieses e facilitar a inclusão de pessoas expatriadas e de imigrantes. Sugere-se que organizações ligadas ao turismo brasileiro e instituições públicas que trabalham em políticas direcionadas à promoção do Brasil como destino de viagem valorizem a cultura nacional, sem reforçar o estigma preconceituoso e machista que objetifica a mulher brasileira. 
O presente estudo implica a reflexão crítica sobre a desigualdade de gênero nas organizações e sobre as constantes violências simbólicas vivenciadas por mulheres, dentro e fora do ambiente laboral, quer em seu país de origem, quer no exterior. Denuncia-se, portanto, o olhar sexista, xenofóbico e misógino voltado para profissionais mulheres. Disponibilizam-se alguns subsídios para que organizações brasileiras e de outros países pensem e desenvolvam práticas que inibam todas as formas de assédio, preconceito e discriminação, zelando tanto pelo respeito individual, quanto por sua própria imagem frente ao público de consumidores/as e demais stakeholders.

Esta pesquisa almeja contribuir para o avanço profissional de mulheres com equidade e para o fomento de oportunidades de trabalho decente, independente do país de atuação. Na perspectiva da equidade, deve-se oferecer possibilidades semelhantes, em consonância com as necessidades específicas de cada grupo social. Indica-se que as empresas promovam políticas e práticas que ampliem as oportunidades para mulheres e, consequentemente, provoquem nelas maior satisfação, comprometimento e bem-estar com a organização (Bader et al., 2018; Shortland \& Perkins, 2020).

Sugere-se que as empresas revejam políticas e práticas que interferem na igualdade de gênero, estabelecendo indicadores que promovam um ambiente justo para todas as pessoas, garantindo canais de denúncia seguros e investigações transparentes para casos de discriminação e assédio. Reconhecer a violência de gênero e o assédio como problemas organizacionais e discutir as falhas nos processos são passos fundamentais na busca por igualdade. Deve-se considerar que as mulheres são um grupo historicamente prejudicado na ordem social e que as organizações podem contribuir para uma sociedade futura mais equilibrada. Esta pesquisa apresenta contribuições para a literatura de relações de trabalho e gestão de pessoas, ao tratar da vivência de um grupo social que fomenta debates sobre privilégios e prejuízos, marcados por gênero e nacionalidade, e ao evidenciar a urgência de se formularem políticas em prol da equidade de gênero nas organizações.

Embora a justiça brasileira considere serem necessárias, para se caracterizar o assédio moral, atitudes a longo prazo, o presente estudo, evidencia como desnecessária a demarcação temporal para mostrar as relações de poder, manipulação e humilhação experienciadas por mulheres. Não sendo intenção desta pesquisa reunir denúncias, isenta-se requerer a produção de provas com situações ocorridas ao longo dos anos. Qualquer atitude depreciativa já é suficiente para se considerar um assédio moral ou sexual. Entende-se, no entanto, que essa consideração, à luz do conceito de assédio moral e sexual, possa ser uma limitação da presente investigação.

\section{Referências}

Altman, Y., \& Shortland, S. (2008). Women and international assignments: Taking stock - a 25-year review. Human Resource Management, 47(2), 199-216.

Bader, B., Stoermer, S., Bader, A. K. \& Schuster, T. (2018). Institutional discrimination of women and workplace harassment of female expatriates Evidence from 25 host countries. Journal of Global Mobility, 6(1), 40-58.

Bibi, N. (2016). Role of gender diversity in organizational effectiveness and its implications. International Review of Management and Marketing, 6(4), 80-85.

Borges, L. de O. \& Peixoto, T. P. (2011). Ser operário da construção civil é viver a discriminação social. Revista Psicologia: Organizações e Trabalho, 11(1), 21-36.

Brookfield Global Relocation Services (BGRS). (2016). Global Mobility Trends Survey-2016. New York: Brookfield.

Calderon, P. A. L., Guedes, A. L. M., \& de Carvalho, R. W. (2016). Gestão internacional de recursos humanos: adaptabilidade intercultural na expatriação de brasileiros. Internext, 11(2), 6-20.

Caligiuri, P. M., Joshi, A., \& Lazarova, M. (1999). Factors influencing the adjustment of women on global assignments. International Journal of Human Resource Management, 10(2), 163-179. 
Cheeseborough, T., Overstreet, N., \& Ward, L. M. (2020). Interpersonal Sexual Objectification, Jezebel Stereotype Endorsement, and Justification of Intimate Partner Violence Toward Women. Psychology of Women Quarterly, 44(2), 1-14.

Dawson, G. S., Ho, M. W., \& Kauffman, R. J. (2015). How are C-suite executives different? A comparative empirical study of the survival of American chief information officers. Decision Support Systems, 74(June), 88-105. https://doi.org/10.1016/j.dss.2015.03.005

Duarte, G., \& Spinelli, L. M. (2019). Estereótipos de gênero, divisão sexual do trabalho e dupla jornada. Revista Sociais \& Humanas, 32(2), 126-145.

Eccel, C. S., \& Grisci, C. L. I. (2011). Trabalho e Gênero: a produção de masculinidades na perspectiva de homens e mulheres. Cadernos EBAPE.BR, 9(1), 57-78.

Ezzedeen, S. R., Budworth, M. H., \& Baker, S. D. (2015). The glass ceiling and executive careers: Still an issue for pre-career women. Journal of Career Development, 42(5), 355-369.

Freitas, M. E, de. (2001). Assédio moral e assédio sexual: faces do poder perverso nas organizações. Revista de Administração de Empresas, 41(2), 8-19.

Fraga, A. M., Prestes, V. A., \& Grisci, C. L. I. (2019). Estratégia de viver a vida de uma trabalhadora expatriada à luz da estratégia existencial consumista. Revista Gênero, 20(1), 34-55.

Fraga, A. M., \& Rocha-de-Oliveira, S. (2020). Mobilidades no labirinto: tensionando as fronteiras nas carreiras de mulheres. Cadernos EBAPE. BR, 18(spe), 757-769.

Fidelis, D. Q., \& Mosmann, C. P. (2013). A não maternidade na contemporaneidade: um estudo com mulheres sem filhos acima dos 45 anos. Aletheia, 42, 122-135.

Gallon, S. Scheffer, A. B. B., Gomes, J., \& Corte, V. F. D. (2019). As Diferenças Culturais e Socioeconômicas e o Impacto na Internacionalização Empresarial: um estudo comparativo entre duas empresas multinacionais. Desenvolvimento em Questão, 17 (49), p. 222-246.

Gomes, M. S. (2013). O Imaginário social <Mulher Brasileira> em Portugal: uma análise da construção de saberes, das relações de poder e dos modos de subjetivação. Dados - Revista de Ciências Sociais, 56(4), 867-900.

Hirigoyen, M.-F. (2001). El acoso moral en el trabajo. Distinguir lo verdadero de lo falso. Revista Del Ministerio de Trabajo Y Asuntos Sociales, (1999), 154-157.

Hryniewicz, L. G. C., \& Vianna, M. A. (2018). Mulheres em posição de liderança: obstáculos e expectativas de gênero em cargos gerenciais. Cadernos EBAPE.BR, 16(3), 331-344.

Insch, G. S., Mcintyre, N., \& Napier, N. K. (2008). The expatriate glass ceiling: The second layer of glass. Journal of Business Ethics, 83(1), 19-28.

Janssens, M., Cappellen, T., \& Zanoni, P. (2006). Successful female expatriates as agents: Positioning oneself through gender, hierarchy, and culture. Journal of World Business, 41(2), 133-148.

Joshi, A., Son, J., \& Roh, H. (2015). When Can Women Close the Gap? a Meta-Analytic Test of Sex Differences in Performance and Rewards. Academy of Management Journal, 58(5), 1516-1545.

Kemp, L. J., \& Rickett, B. (2017). The lived experiences of foreign women: Influences on their international working lives. Gender, Work \& Organization, 25(4), 343-360.

Langinier, H., \& Froehlicher, T. (2016). Context Matters: Expatriates' Adjustment and Contact with Host Country Nationals in Luxembourg. Thunderbird International Business Review, 60, 105-119.

Linehan, M., \& Scullion, H. (2004). Towards an understanding of the female expatriate experience in Europe. Human Resource Management Review, 14(4), 433-448.

McLaughlin, H., Uggen, C., \& Blackstone, A. (2017). The Economic and Career Effects of Sexual Harassment on Working Women. Gender \& Society, 31(3), 333-358.

Nunes, A. R., \& Casaca, S. F. (2015). As mulheres perante o desafio de uma carreira internacional. Sociologia, Problemas e Práticas, (77), 77-94. 
Oliveira, A. R. de, Gaio, L. E., \& Bonancim, C. A. G. (2009). Relações de gênero e ascensão feminina no ambiente organizacional: um ensaio teórico. Revista de Administração UFSM, 2(1), 80-97.

Polson, E. (2016). Negotiating independent mobility: Single female expats in Bangalore. European Journal of Cultural Studies, 19(5), 450-464.

Prestes, V. A., Grisci, C. L. I., \& Fraga, A. M. (2016). Lifestyles of workers in the expatriation context. Revista Administração Mackeñie, 17(3), 39-59, maio/jun. 2016.

PwC. (2015). Developing Female Leaders: Addressing Gender Bias in Global Mobility. Austrália, Mar.

2015. Disponível em: < http://www.pwc.com/gx/en/women-at-pwc/internationalwomensday/nextgen-diversity-publication.jhtml> Acesso em: 15 abr. 2015.

Rydzik, A., \& Anitha, S. (2020). Conceptualising the agency of migrant women workers: resilience, reworking and resistance. Work, Employment and Society, 34(5), 883-899.

Rodriguez, J. K., \& Ridgway, M. (2019). Contextualizing privilege and disadvantage: Lessons from women expatriates in the Middle East. Organization, 26(3), 391-409.

Sang, K. J. C., \& Calvard, T. (2019). 'I'm a migrant, but I'm the right sort of migrant': Hegemonic masculinity, whiteness, and intersectional privilege and (dis)advantage in migratory academic careers. Gender, Work \& Organization, 26(10), 1-20.

Schnurr, S., Zayts, O., Schroeder, A., \& Le Coyte-Hopkins, C. (2019). 'It's not acceptable for the husband to stay at home'. Taking a discourse analytical approach to capture the gendering of work. Gender, Work \& Organization, 27(3), 1-21.

Shortland, S., \& Perkins, S. J. (2020). Women's expatriate careers: losing trust in organisational equality and diversity policy implementation?. Journal of Global Mobility, 8(2), 183-208.

Slobodin, O. (2019). "Out of time": A temporal view on identity change in trailing spouses. Time \& Society, 28(4), 1-20. doi:10.1177/0961463x17752283Stewart, D. W., \& Shamdasani, P. (2016). Online Focus Groups. Journal of Advertising, $0(0), 1-13$.

Tanure, B., Barcellos, E. P., \& Fleury, M. T. L. (2009). Psychic distance and the challenges of expatriation from Brazil. The International Journal of Human Resource Management, 20(5), 1039-1055.

Tharenou, P. (2008). Disruptive decisions to leave home: Gender and family differences in expatriation choices. Organizational Behavior and Human Decision Processes, 105(2), 183-2000.

Tonelli, M. J. (2018). O desafio da diversidade. GV Executivo, 17(4), 34-37. 